\title{
NUMERICAL ANALYSIS OF THE HYDRAULIC TRANSIENT RESPONSE IN THE PRESENCE OF SURGE TANKS AND RELIEF VALVES
}

\author{
Alireza Riasi, School of Mechanical Engineering, University of Tehran, Tehran 11155-4563; Email: \\ ariasi@ut.ac.ir \\ Pedram Tazraei, Department of Mechanical Engineering, Texas A\&M University, College Station, TX \\ 77843-3120; Email: ptazraei@tamu.edu (Corresponding Author)
}

\begin{abstract}
Water hammer as a critical consequence of unsteadiness may take place in the penstock of the hydroelectric power plants. Hence, the unsteady flow analysis is important to identify undesirable pressure variations and to take preventive actions toward guaranteeing safe operation of the power plant. Chief among these actions are the installation of a surge tank and relief valve, and the transient flow behavior in the presence of protective devices is investigated herein. The method of characteristics is employed to numerically solve the equations governing the transient flow through channels. Also, in order to better resolve the transient behavior, unsteady friction effects have been considered. Validation of the developed computational code is carried out through comparison of the computed transient pressures with those measured at Karun-III Hydropower Plant. According to the results obtained for MONJ Hydropower Station, when only one turbine is in operation, the surge tank decreases the pressure rise within the spiral case and the turbine overspeed by $22 \%$ and $6 \%$, respectively. While the percentages associated with employing a proper surge relief valves are accordingly $12 \%$ and $14 \%$. This study substantiates how surge relief valves can be used instead of an expensive surge tank to relieve the transient response.
\end{abstract}

Keywords: hydropower plant; hyperbolic PDE; relief valve; surge tank; transient flow; unsteady friction.

\section{INTRODUCTION}

The use of fossil fuels for electricity generation has declined since the late 1970s when oil prices rose sharply [1]. Accordingly, the U.S. Energy Information Administration (EIA) estimates that about $21 \%$ of the world electricity generation was from renewable energies in 2011, with a projection for nearly $25 \%$ in 2040 [2]. Of the 5.4 trillion kilowatt-hours of the new renewable generation added over the projection period, 2.8 trillion kilowatt-hours (52 percent) is attributed to hydroelectric power and 1.5 trillion kilowatt-hours (28 percent) to wind energy [2]. Hence, renewable energies are the fastest-growing source of electricity generation in the IEO2013 Reference case. The contribution of clean and renewable hydroelectric power in the future is expected 
to grow mainly due to the increase of hydropower capability. Therefore, to obtain an optimal design of a specific hydraulic network, and also in order for the system to avoid potentially devastating consequences, it is of importance to scrutinize the transient flow in hydropower plants.

There is a bunch of incidents of penstock failure in hydropower plants throughout the world, the Oneida Station Hydropower plant in the USA, the Lapino Hydropower plant in Poland, and the Oigawa Hydropower plant in Japan, to name a few [3,4]. Since safe operation of power systems is vital, drastic measures are yet to be taken in this respect. In this way, a comprehensive analysis of the water hammer problem can play a key role in the design of hydroelectric power plants working under various operating conditions.

In recent years, various fast transient flow problems have been dealt with in the literature ranging from incidences encountered in industrial settings [5-7] to biologically issues such as the blood hammer [8-9]. The common denominator of all these problems is the existence of a disturbing factor within the system. For example, in a hydroelectric power plant, disturbances are generally caused by various turbine operating points, such as start up, load acceptance, and load rejection [10]. Consequently, all these factors necessitate the use of protective equipments, such as surge tanks [11-13] and pressure relief valves [14].

Surge tanks are commonly used both upstream and downstream of hydropower plant's waterways. They are designed so that the pressure inside the hydraulic system remains nearly constant. Constant transient pressure amplitude in the system is fulfilled by allowing water out of the system during high-pressure transients and adding water during low-pressure transients, provided the surge tank is located where the water level elevation becomes tantamount to the hydraulic grade line elevation [15]. Likewise, relief valves are meant to continuously regulate the fluid flow, and to relieve the overpressures formed within the system. A pressure relief valve opens and closes at designated pressures, for each of which the opening and closing times are specified separately through a control system. The opening and closing times are unique to each hydraulic system. However, the usage of relief valves must be done with caution as an inappropriate selection can even worsen a system's transient response [16]. Having a low valve inertia or a highly responsive control system for a pressure relief valve is of crucial importance, in the sense that it must respond as quickly as possible to the detected overpressures [17].

There is also a rich body of works on the design and application of the water hammer protective devices in the hydraulic circuits. Joukowsky [18] is mentioned among the first authors who investigated the water hammer protection devices. Various techniques for controling transient response, ranging from optimization of the system to the installation of dedicated devices, have been introduced in the literature [12,19]. Bong and Karney [20] studied on the optimal location and size of surge tanks and pressure relief valves for a certain 
hydraulic network. Calamak [21] also worked on the protective measures against the transient flow conditions in the Erfelek hydropower plant.

The Computational Fluid Dynamics (CFD) has reached a level of maturity in recent decades. This powerful tool is being widely used for various design and engineering purposes ranging from modeling the complex blood flows to simulating the unsteady flows in turbomachinery [22]. It has also been widely employed to simulate hydraulic transients in parallel with the advancement of mathematical capabilities and numerical methods. For example, a full-three-dimensional model for the water hammer analysis in axial turbines has been introduced in [23] to resolve the complex flow behavior of the turbine, particularly at the offdesign operating conditions. A powerful and robust method for solving the nonlinear partial differential equations of the water hammer is the method of characteristics (MOC) which found its way into the literature by Monge in 1789. Moreover, its superiority over other numerical schemes has been demonstrated in terms of consistency with the physics and computational cost [24]. Formerly, the classical water hammer equations together with the steady state skin friction equation were being used to simulate the transient flow occurring in hydropower plants. However, the unsteady friction effects greatly impact the transient behavior of the flow [2527], which, in turn, substantiate the use of dynamic friction models. Accordingly, Azoury et al. [28] used the MOC together with the turbulent friction condition to analyze the effect of valve closure schedule on the water hammer.

It is worth mentioning that, in the previous works, the effect of employing different surge protection devices on the transient behavior of a real hydropower plant considering turbine pressure rise and overspeed has not been studied. So the main objective of the present study is to find how the transient response of a hydropower station can be controlled via different protective devices, such as surge tanks and relief valves. To this end, the water hammer problem in the MONJ Hydropower Station has been simulated using the method of characteristics considering the unsteady friction effects. Actually, the novelty of this work lies in the inclusion of such protective devices into simulating a real hydropower plant and studying their corresponding effects. The governing equations, continuity and momentum equations are numerically solved along the waterways. To validate the accuracy of the developed computational code, the transient flow behavior of a real-world case study (the Karun III Hydropower Plant) is considered. Moreover, the maximum and minimum piezometric grade lines along the waterway have been compared with the waterway elevation profile to detect the points which are prone to water column separation. 


\section{MATHEMATICAL MODEL AND NUMERICAL SCHEME}

\subsection{Governing Equations}

Continuity and momentum equations describing the unsteady flows in the one-dimensional form can be expressed as the following hyperbolic partial differential equations [10]:

$$
\begin{aligned}
& \frac{\partial H}{\partial t}+V \frac{\partial H}{\partial x}+\frac{a^{2}}{g} \frac{\partial V}{\partial x}=0 \\
& \frac{\partial V}{\partial t}+V \frac{\partial V}{\partial x}+g \frac{\partial H}{\partial x}+\frac{4}{\rho D} \tau_{w}=0
\end{aligned}
$$

in which, the convective terms can be neglected due to the small Mach number $(V / a \ll 1) . H(x, t)$ is the piezometric head, and $V(x, t)$ is the average axial velocity. In the simulation, the wall shear stress is decomposed into the steady and unsteady wall shear stresses as follows:

$$
\tau_{w}=\tau_{w s}+\tau_{w u}
$$

wherein the steady state friction formula (Darcy-Weisbach) is defined as:

$$
\tau_{w s}=\frac{\rho f}{A^{2}} \frac{Q|Q|}{8}
$$

in the equation above, $Q$ is the flow rate, $\mathrm{A}$ is the cross-section area of the conduit, and $f$ is the Darcy-Weisbach friction factor. Pezzinga [29] proposed a model for the unsteady wall shear stress in order to calculate the pressure variations beyond the first wave cycle:

$$
\tau_{w u}=\frac{k \rho D}{4 A}\left(\frac{\partial Q}{\partial t}+\operatorname{sign}\left(Q \frac{\partial Q}{\partial x}\right) a \frac{\partial Q}{\partial x}\right)
$$

where $k$ is the empirical coefficient, and $\operatorname{sign}(x)$ is the sign function. Adding the term containing $\operatorname{sign}(Q \cdot \partial Q / \partial x)$ makes the model applicable to transient flows occurring both upstream and downstream of the hydraulic turbine. With a linear combination of the water hammer equations, a system of the hyperbolic-parabolic partial differential equations is formed (Eq. 5). These characteristic equations describe perturbations movement at speeds $+a$ and $-a$ relative to the fluid along the positive and negative characteristic lines (Fig. 1) [30]:

$$
\begin{gathered}
C^{+}: \frac{d Q}{d t}+\frac{g A}{a} \frac{d H}{d t}+\frac{4 A}{\rho D} \tau_{w}=0 \\
C^{-}: \frac{d Q}{d t}-\frac{g A}{a} \frac{d H}{d t}+\frac{4 A}{\rho D} \tau_{w}=0
\end{gathered}
$$


Moreover, the discretization of Eqs. (5a) and (5b), respectively, along the positive and negative characteristic lines, shown in Fig. 1, reads as follows,

$$
\begin{gathered}
\left(Q_{i}^{n+1}-Q_{i-1}^{n}\right)+C\left(H_{i}^{n+1}-H_{i-1}^{n}\right)+\frac{4 A \Delta t}{\rho D} \tau_{w}^{n}=0 \\
\left(Q_{i}^{n+1}-Q_{i+1}^{n}\right)-C\left(H_{i}^{n+1}-H_{i+1}^{n}\right)+\frac{4 A \Delta t}{\rho D} \tau_{w}^{n}=0
\end{gathered}
$$

in which $\Delta t$ is the time step, $C$ is a constant equal to $g A / a$, superscript $n$ represents the temporal location, and subscript $i$ denotes the spatial location.

\subsection{Boundary Conditions}

In this section, details regarding the boundary conditions and the treatments applied at the boundaries are discussed. The main assumption regarding boundary conditions is imposing constant head at the upstream and downstream reservoirs. To simulate Francis hydraulic turbine as an internal boundary condition, the flow characteristics of the turbine are employed. To do this, the relation between the net head and the flow rate has to be specified. Fluid flow through a Francis turbine depends upon various parameters: net head, the rotational speed of the unit, the wicket gate opening, to name a few. Since no data is available for the turbine characteristics during the transient state, the steady state model test results (Hill charts), representing the relationship between these parameters for the steady state test conditions, can be used for determining the flow rate during the transient state as well. The characteristic curves are also extrapolated to cover the range of small wicket-gate openings because very little data are available for this range.

The positive and negative characteristics equations are valid for the upstream and downstream of the turbine, respectively. In order to investigate the flow behavior, the discretized equations together with the mass conservation before and after turbine are solved simultaneously [31]. It has always been challenging to decide what device, surge tank or relief valve, in what condition should be utilized in the sense that there should be some devices to counteract positive or negative upsurges in the pressure head. In the following subsections, we are to scrutinize how they function and can alleviate the transient response of the flow field.

\subsubsection{Surge Tank}

As discussed earlier, in fast transient fluid flows through pipes, a series of positive and negative pressure waves are observable as a consequence of sudden changes in the boundary conditions. Surge tank is one of the devices used to facilitate a much more gradual temporal change in the velocity within the system and a reduction in the magnitude of the corresponding transient pressure waves. Its mechanism is such that any pressure fluctuation at the surge tank connection causes flow to or from the tank, thereby moderating the pressure surges in the system. 
Moreover, they are one of the most common protective ideas the investigation of which is even more growing toward optimizing its implementation in different flow conditions.

There are different types of surge tanks, each tailored to a particular purpose. The open-end surge tank-the most common one- used in the Monj Hydropower Station has been considered in this study. This is an open chamber or a tank connected to the pipeline which reflects the pressure waves by supplying or storing excess liquid as shown in Fig. 2.

The inclusion of surge tanks in a transient analysis is carried out through modeling them with a particular set of interior boundary conditions. The set of positive and negative characteristic equations, i.e. Eqs. (6a) and (6b), are valid for nodes $i$ and $i+1$, respectively. The continuity equation dictates that

$$
Q_{i}^{n+1}=Q_{i+1}^{n+1}+Q_{s p}^{n+1}
$$

where $Q_{s p}$ is the flow rate in the standpipe (flow in the upward direction is considered positive.) The set of equations describing the behavior of a surge tank is rather complex; hence, to include surge tanks in a transient analysis, it is necessary to make some simplifying assumptions: (1) The pressure losses between nodes $i$ and $i+1$ can be neglected, thus

$$
H_{i}^{n+1}=H_{i+1}^{n+1}
$$

(2) since the length of the standpipe compared to the length of the pipe of the system is usually short, the liquid inside the standpipe may be considered as a lumped mass. Considering that the weight of the liquid in the standpipe is $\rho g A_{s p} L_{s p}$, and the friction force is $\rho g A_{s p} f L_{s p} Q_{s p}^{n}\left|Q_{s p}^{n}\right| /\left(2 g A_{s p}^{2} D_{s p}\right)$, the following differential equation may be written for the acceleration of the flow in the standpipe:

$$
\frac{L_{s p}}{g A_{s p}} \frac{d Q_{s p}}{d t}=H_{i}^{n+1}-\frac{f L_{s p}}{2 g A_{s p}^{2} D_{s p}} Q_{s p}^{n}\left|Q_{s p}^{n}\right|-Z_{s}^{n+1}
$$

where $Z_{s}$ is the height of the water surface in the tank above the datum. The elevation of the liquid surface in the tank above the datum line at the beginning and at the end of each time step can be related to each other by:

$$
Z_{s}^{n+1}=Z_{s}^{n}+\frac{\Delta t}{2 A_{s}}\left(Q_{s p}^{n+1}+Q_{s p}^{n}\right)
$$

Eqs. (6a, b) along with Eqs. (7) to (10) should be solved at the end of each time step for the six unknowns $H_{i}^{n+1}, H_{i+1}^{n+1}, Q_{i}^{n+1}, Q_{i+1}^{n+1}, Q_{s p}^{n+1}$ and $Z_{s}^{n+1}$. 


\subsubsection{Relief valve}

Surge relief valve is generally one of the most economical solutions to control the transient behavior of the system. Like other protective devices, which should be located close to the point where the initial flow changes are initiated, relief valves are commonly mounted on the penstock near the power unit. They open when a prescribed pressure is exceeded, thereby reducing the excess pressure by releasing a volume of fluid from the process and avoiding a sudden change in velocity [32]. Fig. 3 shows a schematic of a pressure relief valve. Different relief valves are available for different applications or operating conditions ranging from relatively inexpensive spring-loaded devices to rather expensive and complicated mechanisms. As mentioned, the common practice is that they are generally located adjacent to the source of disturbance. In addition, pressure relief valves should have little inertia to be able to respond as quickly as possible to the detected overpressure.

The type of valve that is employed here consists of a main body and a control system. Its structure is horizontal including casing, disc, balancing chamber, servomotor, guiding oil chamber, etc. The wicket gate closure is synchronous with the relief valve opening (there is no time delay). The main characteristics of the valve are listed in Table 1, and Fig. 4 shows the opening/closing profile of the valve. According to the physics of fast transient flows, as soon as the pressure at the valve point falls below the lower limit, the valve opens up in response to the pressure upsurge's arrival (Fig. 4). The valve then start closing slowly (with a mild slope) so as not to bring about a transient aftereffect. In this way, optimization of the opening/closing profile of the relief valve is always sought in order to counteract the transient response of the system.

The positive and negative characteristic equations are respectively valid for the nodes $i$ and $i+1$. The continuity equation is

$$
Q_{i}^{n+1}=Q_{i+1}^{n+1}+Q_{R . V}^{n+1}
$$

whrere $Q_{\mathrm{R} . \mathrm{V}}^{n+1}$ is the relief valve discharge. It is assumed that the pressure losses between nodes $i$ and $i+1$ is negligible, thus

$$
H_{i}^{n+1}=H_{i+1}^{n+1}
$$

Finally, the $C_{V}$ coefficient, which is the valve sizing coefficient determined by testing, relates the flow and pressure conditions in the valve characteristic equation by the following basic relation:

$$
Q_{R . V .}^{n+1}=C_{v} \sqrt{H_{i}^{n+1}}, C_{v}=2.69 \times 10^{-3} \times Y_{R V}
$$


in which $Y_{R V}$ is the relief valve opening in percentage. Again, considering Fig. 5., Eqs. (6a, b) with Eqs. (11) to (13) should be solved simultaneously at the end of each time step for the five unknowns $H_{i}^{n+1}, H_{i+1}^{n+1}, Q_{i}^{n+1}, Q_{i+1}^{n+1}$ and $Q_{\mathrm{R} . \mathrm{V} \text {. }}^{n+1}$.

\subsection{Model Verification and Validation}

In this section, validation of the developed computational code is carried out in detail through comparison of the pressure oscillations at the spiral case and the draft tube of the turbine due to a load rejection with the one reported for the transient flow in the Karun-III hydropower plant. The Karun-III hydropower plant is located about 28 kilometers east of the city of Izeh in Khuzestan province on the Karun River in the south of Iran. The power plant consists of 8 Francis units, each 250MW. Four surge tanks on the upstream and eight surge tanks on the downstream water ways have been erected to avoid potentially devastating consequences of the water hammer. The profiles of power plant and also a schematic of the upstream and downstream water passages are shown in Fig. 6. The main data of this power plant are listed in Table 2. According to Fig. 7, both the pressure amplitude and the pressure phase are accurately resolved by the approach. Uncertainties in the estimation of friction factor, waterway diameter, waterway length, and especially the wave speed cause some discrepancies between the computed and the measured data. As a matter of fact, the wave propagation speed varies along the concrete and steel lined tunnel and depends on the elastic properties of the fluid and pipe material, as well as on the geometry and anchorage of the pipe [33].

\section{RESULTS AND DISCUSSION}

As yet, several control mechanisms for the transient response of the hydraulic system have been introduced. In this section, the discussion on the efficacy of these proposed changes and improvement strategies implemented in the system layout, whether installation of a surge tank or a relief valve, is covered. To evaluate the superiority of each mechanism in terms of the overpressure control under a specific operating condition, a case study of the Iran MONJ Hydropower Station has been considered. This power station is a $5.36 \mathrm{MW}(2 \times 2.68 \mathrm{MW})$ Francis type hydropower plant located in Iran.

It is well reported that the water hammer problem is much more serious in the case of having a long upstream waterway as is the case with the MONJ Hydropower Station. Hence, it should be paid attention to choosing the best protective device alleviating the transient response of the system to an instantaneous load rejection. The schematic of the MONJ Hydropower Station with the connecting pipe properties are shown in 
Fig. 8. The main characteristics of this hydropower plant are listed in Table 3, and waterway level is sketched in Fig. 9. A surge tank with a diameter of $3 \mathrm{~m}$ is located at a distance of $1260 \mathrm{~m}$ from the upstream reservoir and at an elevation of $945 \mathrm{~m}$ above sea level. Moreover, diameter and length of the standpipe are $2 \mathrm{~m}$ and $15 \mathrm{~m}$, respectively. The friction factor and the wave speed through waterways were recommended by the designer to be 0.01 and $1050 \mathrm{~m} / \mathrm{s}$, respectively.

In this case study, the transient flow is generated due to a quick closure of the guide vanes, generator load rejection, of the two units fed from a main penstock. The wicket gates are scheduled to close in 8 seconds, as a result of which pressure dramatically increases in the spiral case. In Table 4, two critical test cases are summarized.

The effect of different surge protection devices on the spiral case pressure fluctuations due to load rejection is shown in Fig. 10a for the case no.1. And the same results are presented in Fig. $10 \mathrm{~b}$ for pressure fluctuations in the draft tube. According to Fig. 10, the surge tank considerably dampens the maximum pressure at the spiral case by $22 \%$. But, for the case of relief valve, a sudden pressure drop occurs due to almost sudden opening of valve and then the maximum pressure decreases by $12 \%$. The minimum pressure at the entrance of the draft tube just below the runner outlet is almost the same for the different surge protection devices (Fig 10b).

The transient results, for which surge tanks and relief valves were not taken into account, are listed in Table 5. It is clear that this condition is very risky for the power station because the pressure rise and the turbine overspeed are much higher than the allowable magnitudes of 140 meter of water for the pressure and $155 \%$ of the nominal turbine speed for the overspeed. On the threshold of transient, due to the negative pressure waves coming back from the turbine to the upstream reservoir, if the pressure head of the flow-hydraulic grade linedrops below the liquid level, column separation will definitely occur.

According to the results, rapid closure of the guide vanes would result in approximately $185.17 \mathrm{~m}$ of the maximum pressure head and $-3.82 \mathrm{~m}$ of the minimum pressure head in the system. The maximum head 185.17 $\mathrm{m}$ is extremely high, and this may cause a pipe to rupture or impose an extra cost for a pipe of enhanced strength. Transient cavitating flow usually occurs as a result of the low pressures during transients. Cavitation significantly changes the water hammer waveform, and the water hammer equations developed for a pure liquid flow will be no longer valid for the transient two-phase flow [34]. The large negative pressures in the case of not using protective devices imply that the response is unacceptable. 
The difference in elevation of the hydraulic grade line and the waterway profile defines the static pressure distribution along the waterway. In Fig. 11, the hydraulic grade line is plotted for the case no. 2. It shows that when no protective device is employed, the hydraulic grade line falls below the waterway elevation at distances of $200 \mathrm{~m}$ and $1300 \mathrm{~m}$ from the reservoir. Consequently, the cavitation and water column separation will most likely occur [34]. But as shown in Fig. 12, in the case of surge tank, the minimum piezometric head lies above the liquid level, which ensures that there is a positive pressure all along the water path. According to Fig. 13, it is worth mentioning that a critical hydraulic response is resulted at a distance $200 \mathrm{~m}$ from the reservoir (the hydraulic grade line and the liquid level get close to each other) when the relief valve is used. Increasing the distance between the two curves is possible through optimizing the opening/closing profile of the valve; as a result, the critical response can be avoided.

The same results are presented in Table 6 when the surge tank is used. It is illustrated that the magnitude of the overpressure and overspeed decrease. Fig. 12 shows the range of maximum and minimum pressures for the system along the penstock during the full load rejection with the originally specified wicket-gate closure law. It shows qualitatively how surge tanks can prevent the column separation that is a common result of a load rejection. For this case, case no. 2 is plotted in Fig. 12 and as is evident, the occurrence of the column separation is unexpected.

Moreover, at the point where the turbine is placed, the maximum difference between the maximum piezometric pressure curve and the waterway profile (i.e., the maximum positive pressure) corresponds to the case in which no protective device is implemented. Control strategies, the surge tank and relief valve, cause a reduction in the aforementioned difference, and the reduction is more pronounced in the case of surge tank. Generally, the slope of minimum and maximum hydraulic grade lines decreases as the control devices are employed, which, in turn, lead to a uniform pressure distribution along the waterway. In other words, installation of the relief valve next to the turbine really makes a difference, as shown in Table 7 . It is clear that the transient response is improved, the overspeed considerably decreases (outflow from the relief valve can cause even more reduction in the overspeed). The comparison between the hydraulic grade line and pipe elevation is shown in Fig. 13, according to which, the operation of an appropriately designed relief valve can limit maximum and minimum transient pressure heads along the pipeline. Also, similar to the surge tank case, column separation will not happen in this case. 


\section{CONCLUSION}

The number of run-of-river hydropower plants in the world is rapidly increasingly and the water hammer problem as a limiting factor is a major problem needing attention. In hydropower plants, pressure surges can propagate in the hydraulic system as a result of any quick change in the liquid velocity. As a case in point, working fluid comes to a halt in an almost immediate fashion as a result of a sudden load rejection in the penstock of a hydroelectric power plant. Hence, this condition necessitates the employment of a surge protective device to counteract these effects. The primary objective of this study is to develop a better insight into the dynamics of transient flow in the hydropower plants' waterways considering measures like installation of surge tanks and relief valves.

In this paper, a computational code is developed based on the method of characteristics considering the dynamic friction. The standard assumptions include valid algebraic head loss relations for the steady and unsteady friction models, constant wave speed, and dominantly one-dimensional transient flow. This study proves how surge relief valves can provide a surge suppression compared to surge tanks and can be used in place of an expensive surge tank to improve the transient response of the system. It should be noted that in the case of surge tank, unless the tank is voluminous enough to accommodate large pressure fluctuations, its efficacy is in doubt. On the other hand, small relief valves are capable of being mounted in large pipelines, in that they can handle high velocities for a short time period. As discussed, the main sources of the uncertainties in this study are: (a) the wave speed may change along the waterways and is not constant, (b) the correlations for predication of unsteady friction are purely empirical and are prone to some uncertainties, and (c) the steady state hill charts are assumed to be valid for the transient simulation.

For the future works, the opening/closing profile of the relief valve should be optimized based on the maximum pressure rise and the overspeed.

\section{ACKNOWLEDGMENTS}

The writers wish to thank the Iran National Science Foundation for financial support under Project no.91003849 and also the Iran Water Resources Company for their help and support.

\section{NOMENCLATURE}

$a \quad$ Acoustic wave velocity

A Pipe cross section

$A_{s} \quad$ Cross section area of surge tank 
$A_{s p} \quad$ Cross section area of standpipe

C Constant

$\mathrm{C}^{+} \quad$ Positive characteristic line

$C^{-} \quad$ Negative characteristic line

$C_{v} \quad$ Valve Coefficient

$D \quad$ Pipe diameter

$D_{s p} \quad$ Standpipe diameter

$f \quad$ Darcy-Weisbach friction factor

$g \quad$ Gravity acceleration

H Piezometric head

$k \quad$ Empirical coefficient for Brunone model

$L_{s p} \quad$ Standpipe length

$Q \quad$ Flow rate

$Q_{R . V .} \quad$ Relief valve outflow

$Q_{s p} \quad$ Flow rate in standpipe

$t \quad$ Time

$V \quad$ Average axial velocity

$X \quad$ Distance along the pipe

$Y \quad$ Pipe elevation above the datum

$Y_{R V} \quad$ Relief valve opening in percentage

$Z_{s} \quad$ Water level in surge tank above the datum

\section{Greek letters}

$\rho g \quad$ Unit gravitational force

$\rho \quad$ Mass density

$\tau_{w} \quad$ Wall shear stress

$\tau_{w s} \quad$ Steady state wall shear stress

$\tau_{w u} \quad$ Unsteady wall shear stress

\section{Subscripts}

$i \quad$ Spatial location

$s \quad$ Steady

$u \quad$ Unsteady

$w \quad$ Wall

\section{Superscripts}

$n \quad$ Temporal location

$+\quad$ Related to positive characteristic

- $\quad$ Related to negative characteristic

\section{REFERENCES}


[1] International Energy Agency, Energy Balances of OECD Countries (2013 preliminary edition), and Energy Balances of Non-OECD Countries (October 2012).

[2] U.S. Energy Information Administration, International Energy Outlook 2013, Chapter 5: Electricity (July $25,2013)$.

[3] A. Adamkowski, Case study: Lapino powerplant penstock failure, J. Hydraul. Eng-ASCE, 127(7) (2001), pp. 541-555.

[4] J. Yang, K. Zhao, L. Li, P. Wu, Analysis on the causes of units 7 and 9 accidents at Sayano-Shushenskaya Hydropower Station, J. Hydroelectric Eng., 30(4), (2011), pp. 226-234.

[5] P. Tazraei, A. Riasi, Quasi-two-dimensional numerical analysis of fast transient flows considering nonNewtonian effects," J. Fluids Eng., 138(1) (2015), 011203.

[6] Q. Zhang, B.W. Karney, L. Suo, A. Colombo, Stochastic analysis of water hammer and applications in reliability-based structural design for hydro turbine penstocks, J. Hydraul. Eng- ASCE, 137(11) (2011), pp. 1509-1521.

[7] P. Tazraei, A. Riasi, Numerical Study of Fast Transient Shear thinning Flows Considering Time Constant Variations of the Carreau Model, (ICMIE'12), Kuala Lumpur, Malaysia (2012), pp. 63-67.

[8] P. Tazraei, A. Riasi, B. Takabi, The influence of the non-Newtonian properties of blood on blood-hammer through the posterior cerebral artery, Math. Biosci., 264 (2015), pp. 119-127.

[9] M. Hammes, M. Boghosian, K. Cassel, S. Watson, B. Funaki, T. Doshi, S.J.M. Akherat, J. Hines, F. Coe, Increased Inlet Blood Flow Velocity Predicts Low Wall Shear Stress in the Cephalic Arch of Patients with Brachiocephalic Fistula Access, PloS one, 11(4) (2016), p.e0152873.

[10] A. Riasi, M. Raisee, A. Nourbakhsh, Simulation of transient flow in hydroelectric power plants using unsteady friction, Strojniski vestnik - J. Mech. Eng., 56(6) (2010), pp. 377-384.

[11]X. Zhang, Y. Cheng, Simulation of hydraulic transient in hydropower systems using the 1-D-3-D coupling approach, J. Hydrodyn., 24(4) (2012), pp. 595-604.

[12]T. E. Kendir, A. Ozdamar, Numerical and experimental investigation of optimum surge tank forms in hydroelectric power plants, Renewable Energy, 60 (2013), pp. 323-331.

[13]R. Klasinc, I. Bilus, Experimental and numerical approach to surge tank improvements, International symposium on water management and hydraulic engineering, paper A100, 2009, pp. 339-48.

[14] Q. Zhang, B.W. Karney, D. L. McPherson, Pressure relief valve selection and transient pressure control, J. Am. Water Works Assoc., 100(8), 2008, pp. 62-69.

[15]H. Methods, T. M. Walski, D.V. Chase, D.A. Savic, W.M. Grayman, S. Beckwith, E. Koelle, Advanced water distribution modeling and management, Heasted Press, USA, First ed., 2003.

[16] K.Q. Zhang, B.W. Karney, D.L. Mcpherson, Pressure-relief valve selection and transient pressure control, J. Am. Water Works Assoc., 100(8) (2008), pp. 62-69.

[17] M.H. Chaudhry, Applied Hydraulic Transients, Van Nostrand Reinhold Company, 1987.

[18] N.E. Joukowsky, Mem. Imperial Academy Soc. of St. Petersburg, 9(5), (1898) (in Russian, translated by O.simin, proc. Amer. Water works Assoc., 24, (1904), pp. 341-424).

[19] B.S. Jung, B.W. Karney, Hydraulic optimization of transient protection devices using GA and PSO approaches. J. Water Res. Pl- ASCE, 132(1) (2006), pp. 44-52.

[20] Bong, S.J., Karney, B.W. Hydraulic optimization of transient protection devices using GA and PSO approaches. Journal of Water Resources Planning and Management, ASCE. 2006, 132(1): 44-52.

[21] M. Calamak, Z. Bozkus, Comparison of performance of two run-of-river plants during transient conditions. J. Perform. Constr. Fac., 27(5) (2013), pp. 624-632.

[22] A. Nikparto, M.T. Schobeiri, Experimental and numerical investigations of aerodynamics on flow around a highly loaded turbine blade with flow separation under steady and periodic unsteady inlet flow condition, ASME Turbo Expo 2016: Turbine Technical Conference and Exposition, 2016.

[23] B.W. Karney, D. McInnis, Efficient calculation of transient flow in simple pipe networks, J. Hydraul. EngASCE, 118(7) (1992), pp. 1014-1030.

[24]E. B. Wylie, V.L. Streeter, L. Suo, Fluid transients in systems, New Jersey: Prentice-Hall, 1993.

[25] B. Brunone, B.W. Karney, M. Mecarelli, M. Ferrante, Velocity profiles and unsteady friction in transient flow, J. Water Res. Pl- ASCE, 126(4) (2000), pp. 236-244.

[26] A. Bergant, A.R. Simpson, J. Vitkovsky, Development in unsteady pipe flow friction modeling, J. Hydraul. Res., 39(3) (2001), pp. 249-257.

[27] W.F., Silva-Araya, M.H., Chaudhry, Unsteady friction in rough pipes, J. Hydraul. Res., 127(7) (2001), pp. 607- 618.

[28] P. H. Azoury, M. Baasiri, H. Najm, Effect of valve-closure schedule on water hammer, J. Hydraul. EngASCE, 112(10) (1986), pp. 890-903. 
[29] G. Pezzinga, Evaluation of unsteady flow resistances by quasi-2D or 1D models, J. Hydraul. Eng-ASCE, 126(10) (2000), pp. 778-785.

[30] M.S. Ghidaoui, S. Mansour, Efficient treatment of the Vardy-Brown unsteady shear in pipe transients, J. Hydraul. Eng-ASCE, 128(1) (2002), pp. 102-112.

[31] A. Bergant, The behaviour of a hydraulic turbomachine during transients, Strojniski vestnik - J. Mech. Eng., 49(3) (2003), pp. 150-160.

[32] L.W. Douglas, Surge control, J. Am. Water Works Ass., 64(7) (1972), pp. 462-466.

[33] A. Nourbakhsh, A. Jaumotte, C. Hirsch, H. Parizi, Turbopumps and pumping systems, Springer Berlin Heidelberg, 2007.

[34] M. Sadafi, A. Riasi, S.A. Nourbakhsh, Cavitating flow during water hammer using a generalized interface vaporous cavitation model, J. Fluids Struct., 34 (2012), pp. 190-201. 


\section{Tables Caption List}

Table 1 Pressure relief valve characteristics

Table 2 The main characteristics of the Karun III hydropower station.

Table 3 The main characteristics of the Monj hydropower Station.

Table 4 The details for the test cases examined.

Table 5 Transient results for load rejection phenomenon (without surge tank and relief valve).

Table 6 Transient results for load rejection phenomenon in the presence of surge tank.

Table 7 Transient results for load rejection phenomenon in the presence of relief valve.

Table 1

\begin{tabular}{|l|c|}
\hline \multicolumn{1}{|c|}{ Parameter } & value \\
\hline Valve diameter [mm] & 400 \\
\hline Design Head [m] & 100 \\
\hline Maximum Head [m] & 180 \\
\hline Full stroke [mm] & 65 \\
\hline
\end{tabular}


Table 2

\begin{tabular}{|l|c|}
\hline \multicolumn{1}{|c|}{ Parameter } & value \\
\hline Rated poerw [MW] & 255 \\
\hline Rated Head [m] & 161 \\
\hline Rated Flow [m $\left.{ }^{3} / \mathrm{s}\right]$ & 172 \\
\hline Rated Rotational Speed [rpm] & 187.5 \\
\hline
\end{tabular}


Table 3

\begin{tabular}{|l|c|}
\hline \multicolumn{1}{|c|}{ Parameter } & Value \\
\hline Rated power [MW] & 2.68 \\
Rated head [m] & 100.0 \\
Rated flow [m³/s] & 3.0 \\
Rotational speed [rpm] & 750.0 \\
Head water level [m] & 983.0 \\
Tail water level [m] & 876.0 \\
Moment of inertia [ton.m ${ }^{2}$ ] & 8.6 \\
Turbine elevation [m] & 878.5 \\
\hline
\end{tabular}


Table 4

\begin{tabular}{ccccc}
\hline $\begin{array}{c}\text { Test } \\
\text { No. }\end{array}$ & $\begin{array}{c}\text { Unit No. } \\
\text { in } \\
\text { operation }\end{array}$ & $\begin{array}{c}\text { Power } \\
(\mathrm{MW})\end{array}$ & $\begin{array}{c}\text { Discharge } \\
\left(\mathrm{m}^{3} / \mathrm{s}\right)\end{array}$ & $\begin{array}{c}\text { Closing } \\
\text { Time } \\
(\mathrm{S})\end{array}$ \\
\hline 1 & 1 & 2.68 & 3.0 & 8.0 \\
2 & 2 & 2.68 & 3.0 & 8.0 \\
\hline
\end{tabular}


Table 5

\begin{tabular}{cccc}
\hline $\begin{array}{c}\text { Test } \\
\text { No. }\end{array}$ & $\begin{array}{c}\text { Max. Pressure } \\
\text { at Spiral Case } \\
(\mathrm{m})\end{array}$ & $\begin{array}{c}\text { Min. Pressure } \\
\text { at Draft Tube } \\
(\mathrm{m})\end{array}$ & $\begin{array}{c}\text { Turbine } \\
\text { Over Speed } \\
\left(\frac{\circ}{\circ}\right)\end{array}$ \\
\hline 1 & 148.06 & -3.57 & 157 \\
2 & 185.17 & -3.82 & 168 \\
\hline
\end{tabular}


Table 6

\begin{tabular}{cccc}
\hline $\begin{array}{l}\text { Test } \\
\text { No. }\end{array}$ & $\begin{array}{c}\text { Max. Pressure } \\
\text { at Spiral Case } \\
(\mathrm{m})\end{array}$ & $\begin{array}{c}\text { Min. Pressure } \\
\text { at Draft Tube } \\
(\mathrm{m})\end{array}$ & $\begin{array}{c}\text { Turbine } \\
\text { Over Speed } \\
(\%)\end{array}$ \\
\hline 1 & 115.0 & -3.31 & 148 \\
2 & 127.4 & -3.69 & 154 \\
\hline
\end{tabular}


Table 7

\begin{tabular}{cccc}
\hline $\begin{array}{l}\text { Test } \\
\text { No. }\end{array}$ & $\begin{array}{c}\text { Max. Pressure } \\
\text { at Spiral Case } \\
(\mathrm{m})\end{array}$ & $\begin{array}{c}\text { Min. Pressure } \\
\text { at Draft Tube } \\
(\mathrm{m})\end{array}$ & $\begin{array}{c}\text { Turbine } \\
\text { Over Speed } \\
\left(\frac{\circ}{0}\right)\end{array}$ \\
\hline 1 & 130.0 & -3.39 & 134 \\
2 & 140.0 & -3.97 & 135 \\
\hline
\end{tabular}




\section{Figures Caption List}

Fig. 1 Positive and negative characteristic lines in one-dimension.

Fig. 2 Diagram of an open-end surge tank with stand pipe.

Fig. 3 Schematic of a typical surge relief valve.

Fig. 4 Pressure relief valve opening and closing profiles.

Fig. 5 Diagram of a surge relief valve.

Fig. 6 (a) Schematic of the waterways and (b) waterways profile detail in Karun 3 Hydropower Station.

Fig. 7 Pressure-time history validation (a) at the spiral case, (b) at the draft tube.

Fig. 8 Schematic of the waterways in MONJ Hydropower Station.

Fig. 9 Pipes elevation of MONJ Hydropower Station from the sea level.

Fig. 10 Effect of different surge protection devices on (a) spiral case pressure and (b) draft tube pressure

Fig. 11 Comparison between the liquid level and maximum and minimum hydraulic grade lines (without surge tank and relief valve).

Fig. 12 Comparison between the pipe profile and maximum and minimum hydraulic grade lines in the presence of surge tank.

Fig. 13 Comparison between the pipe profile and maximum and minimum hydraulic grade lines in the presence of relief valve. 


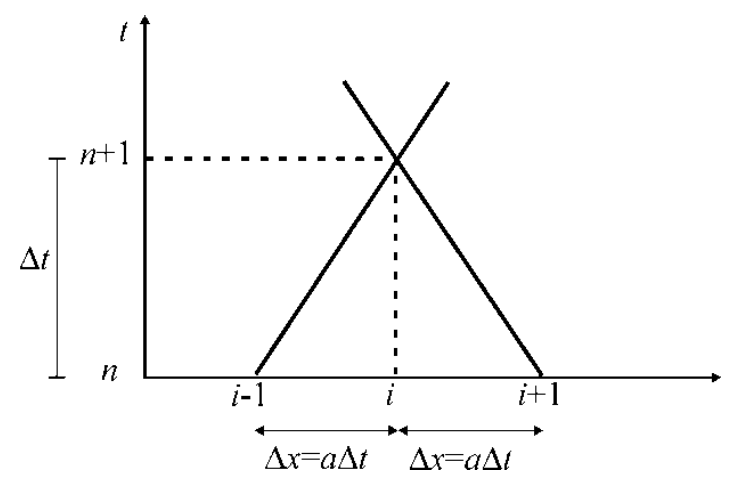

Fig. 1 


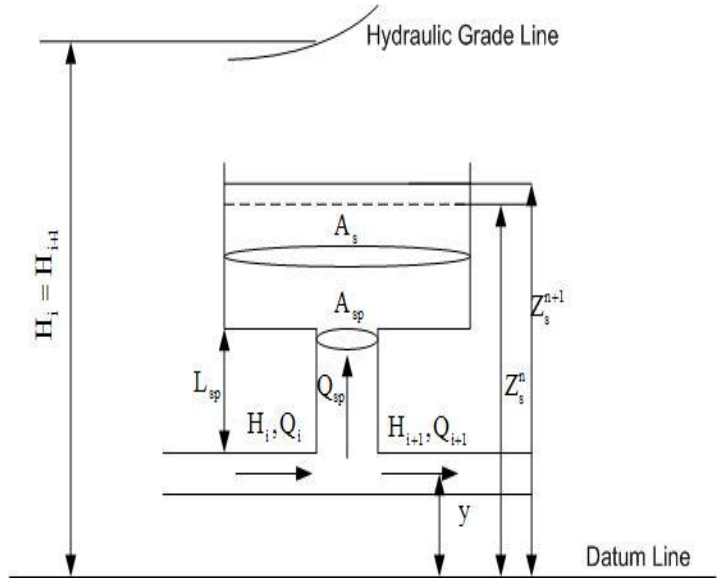

Fig. 2 


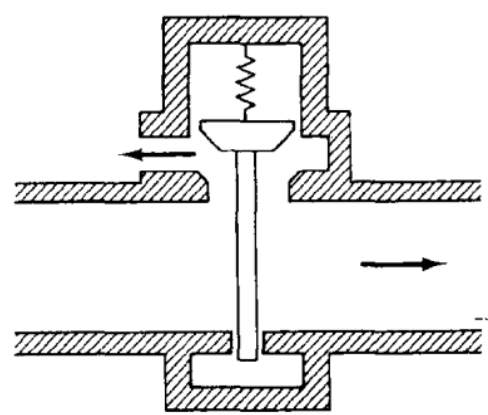

Fig. 3 


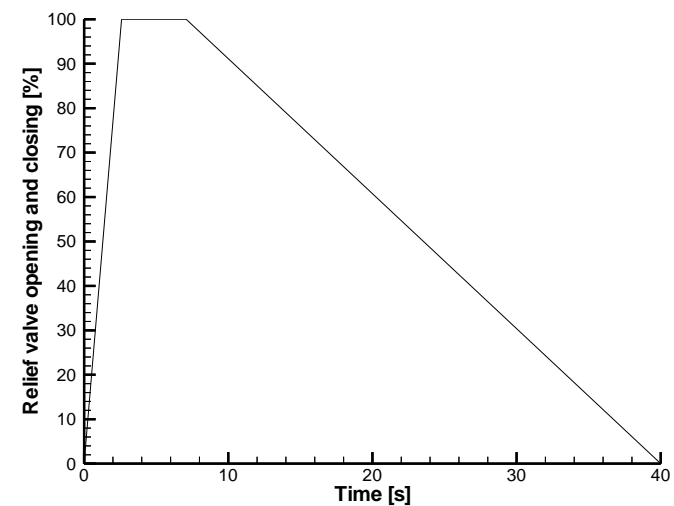

Fig. 4 


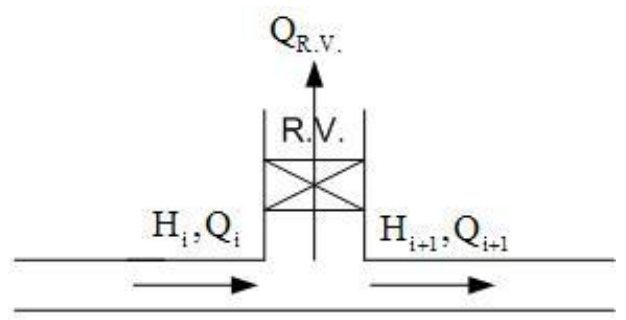

R.V.: Relief Valve

Fig. 5 


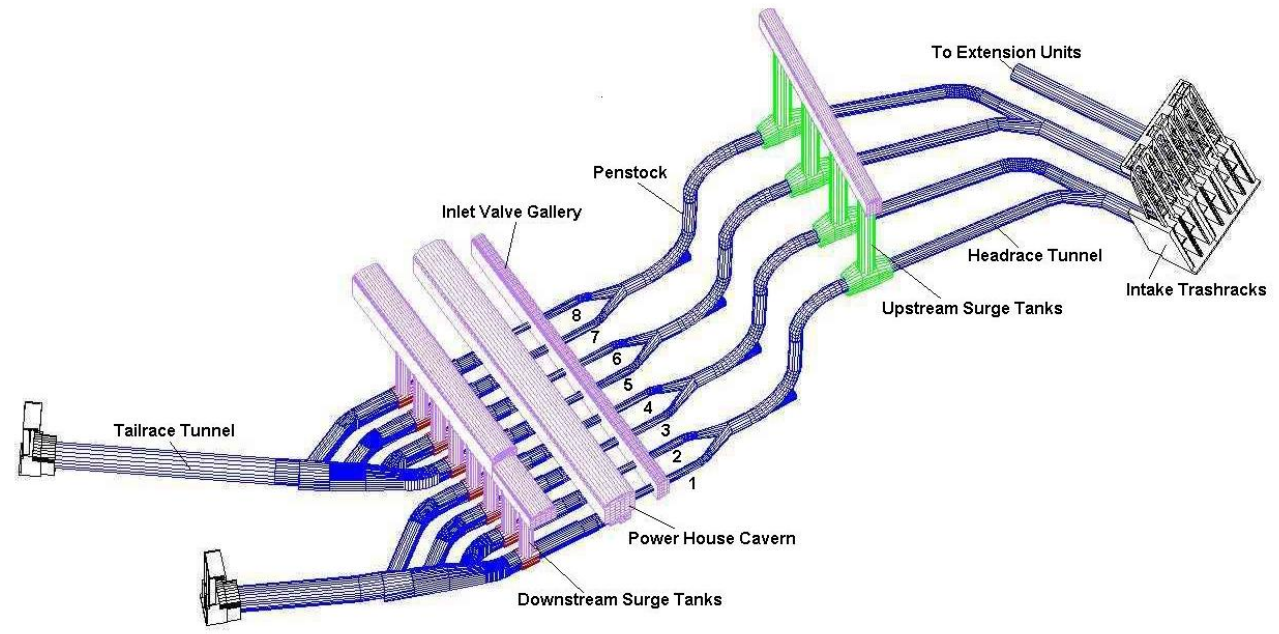

(a)

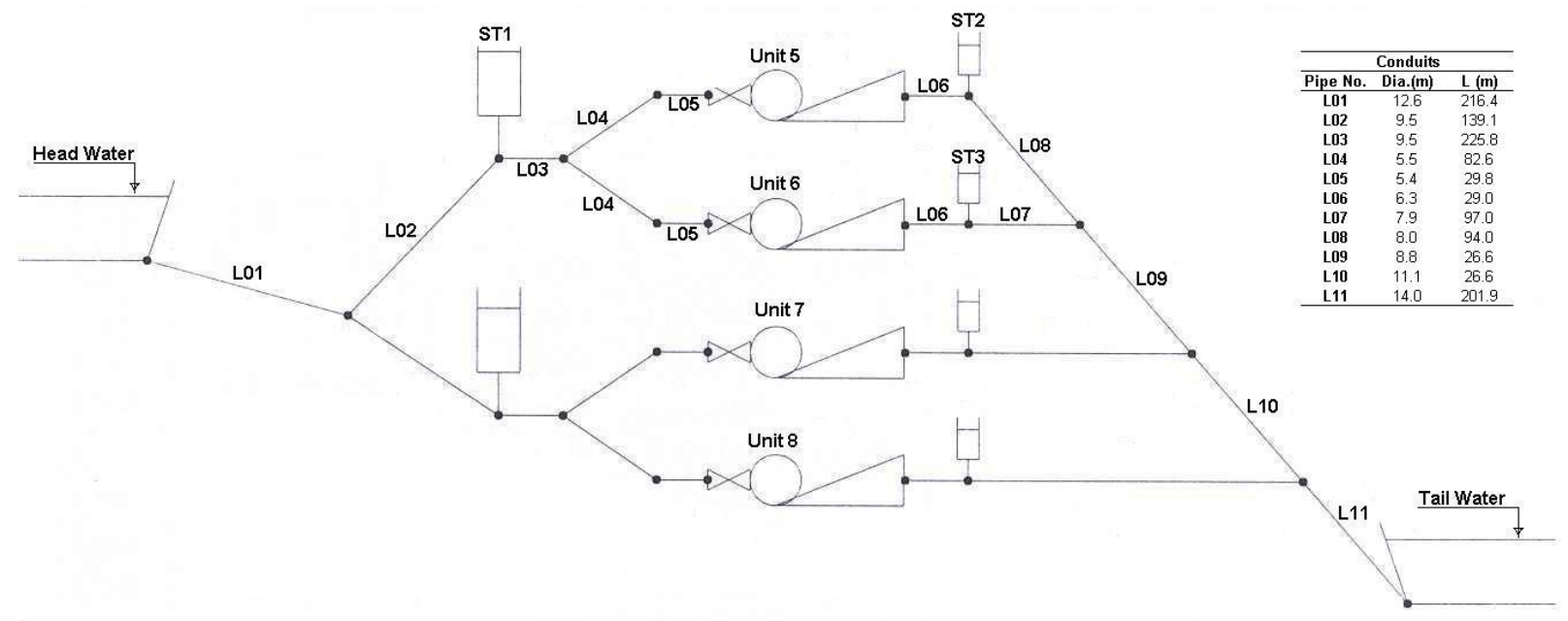

(b)

Fig. 6 


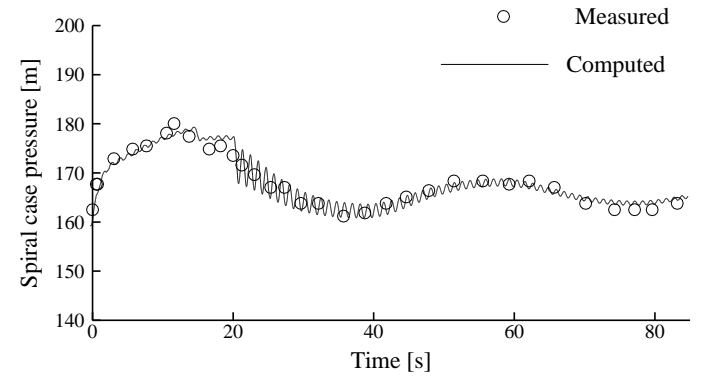

(a) 


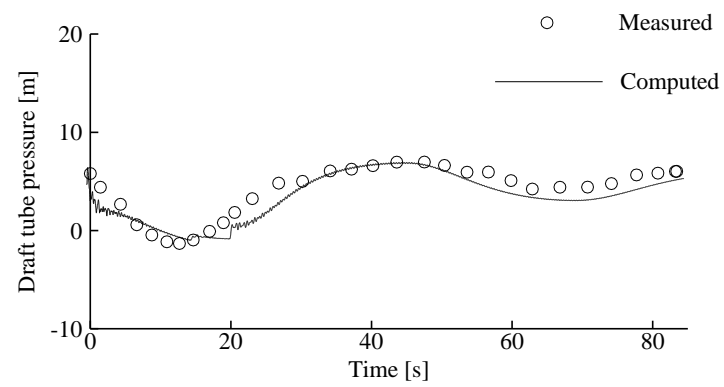

(b)

Fig. 7 


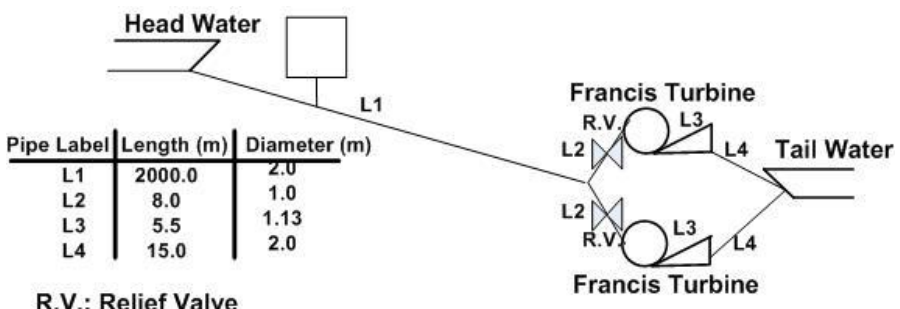

Fig. 8 


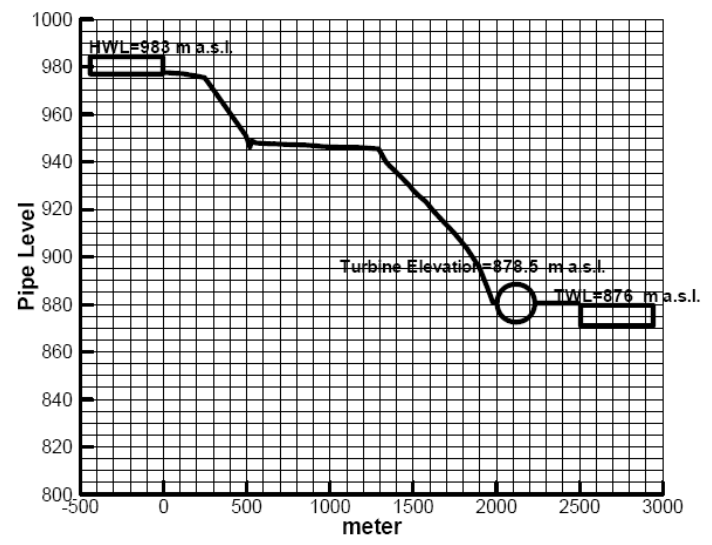

Fig. 9 


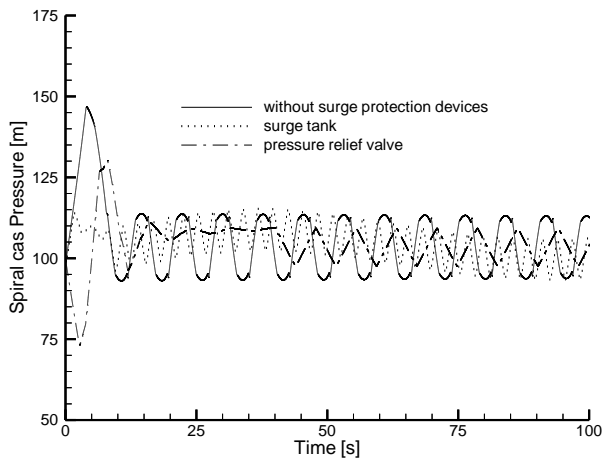

(a)

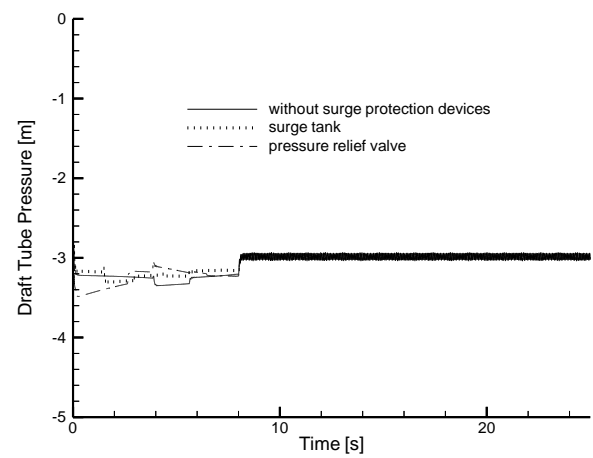

(b)

Fig. 10 


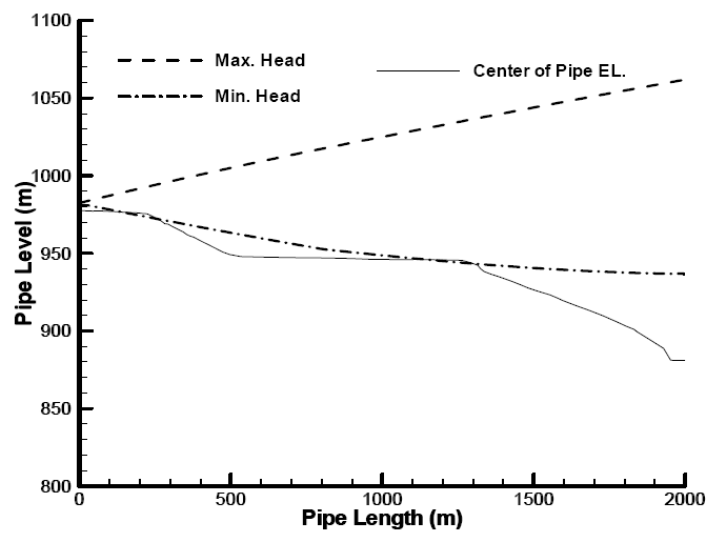

Fig. 11 


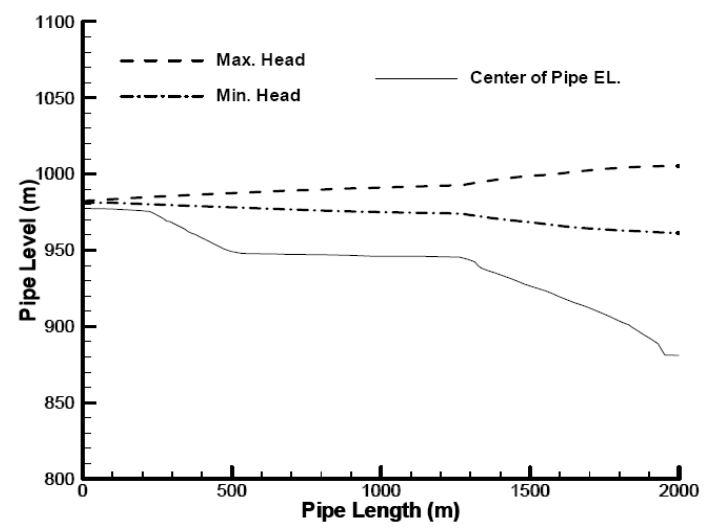

Fig. 12 


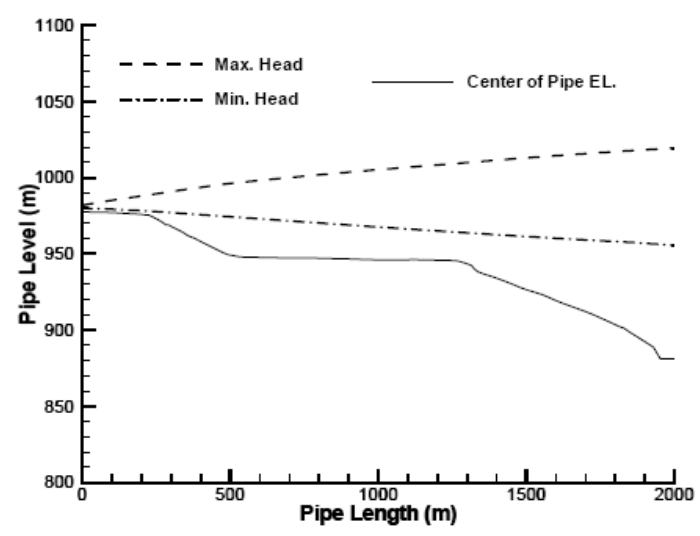

Fig. 13 